\title{
Ambient Pressure Synthesis of Nanostructured Tungsten Oxide Crystalline Films
}

\author{
H. X. Zhang, ${ }^{1}$ B. Q. Yang, ${ }^{1}$ and P. X. Feng ${ }^{1,2}$ \\ ${ }^{1}$ Department of Physics, University of Puerto Rico, P.O. Box 23343, San Juan, PR 00931, USA \\ ${ }^{2}$ Department of Physics, Donghua University, Shanghai 200051, China
}

Correspondence should be addressed to P.X. Feng, peterxianping@vmail.uprrp.edu

Received 5 March 2008; Accepted 28 April 2008

Recommended by Rakesh Joshi

\begin{abstract}
We report the results of the ambient pressure synthesis of tungsten oxide nanowires and nanoparticles on AlN substrates using the hot filament CVD techniques. The morphologic surface, crystallographic structures, chemical compositions, and bond structures of the obtained samples have been investigated using scanning electron microscopy (SEM), X-ray diffraction (XRD), energy dispersive X-ray spectroscopy (EDX), and Raman scattering, respectively. Different morphologies were observed for different substrate temperatures, but otherwise identical growth conditions. The experimental measurements reveal the evolutions of the crystalline states and bond structures following the substrate temperatures. Besides, different substrate materials also affected the tungsten oxide nanostructures. Bundles of wire-type tungsten oxide nanowires with a length of up to $5 \mathrm{~mm}$ were obtained on $\mathrm{Al}_{2} \mathrm{O}_{3}$ substrate. Furthermore, the sensitive properties of the super long nanowires to the gas and different temperature were investigated. The dependence of the sensitivity of tungsten oxide nanowires to the methane as a function of the time was obtained. The sensitive properties of the tungsten oxide nanowires have almost linear relationship with the temperature.
\end{abstract}

Copyright (c) 2008 H. X. Zhang et al. This is an open access article distributed under the Creative Commons Attribution License, which permits unrestricted use, distribution, and reproduction in any medium, provided the original work is properly cited.

\section{INTRODUCTION}

Over the last decade, nanostructured tungsten oxide materials have attracted much interest due to their potential for catalyst [1], gas sensors [2, 3], and electrochromic material applications [4]. Several studies have been conducted by using various techniques, including the oxygen plasma processing [5], plasma sputtering [6], chemical solution [7, 8], sol-gel techniques [9], electron beam evaporation deposition [10], electrochemical etching [11], and the chemical vapor deposition techniques [12]. Most work concerned the synthesis of nanoparticles for catalytic applications based on chemical solution methods [4, 7-9].

Using a simple hot filament CVD technique, we previously synthesized various nanostructured tungsten oxide $\left(\mathrm{WO}_{3}\right)$ films $[13,14]$. The advantage of this technique was that both a.c. and d.c. electrical power supply could be used for heating the substrates. Low electrical power was used, less than $80 \mathrm{~W}$. The temperature of the substrate was easily controlled by adjusting the distance between the substrate and the hot filament, and no extra heater was needed.
In the present work, we address ambient pressure syntheses of tungsten oxide nanoparticles and nanowires, and then the demonstration of their sensing applications. The main advantages of the ambient pressure deposition technique are that the temperature and density of plasma can be independently controlled during deposition. Furthermore, the experimental set-up is easy and effective, and the size of the sample is virtually unlimited. The effect of substrate temperature on the nanostructures of tungsten oxidefilms has also been investigated. Preliminary results of sensing material applications have been obtained.

\section{EXPERIMENTAL SETUP}

The nanostructured tungsten oxide materials were synthesized using a simple hot filament CVD technique. The details of the process were described elsewhere in our previous publications [13, 14]. The tungsten filament acted as a precursor for tungsten oxide, and no catalyst or other tungsten-containing compound precursor was used. Both AlN and $\mathrm{Al}_{2} \mathrm{O}_{3}$ ceramic substrates were used. Prior to the 
experiments, the substrates were ultrasonically washed in the methanol solution for 5 minutes, and dried with helium. After placing the substrate, the chamber was pumped down to $2.0 \times 10^{-5}$ Torr and then fed with the Ar gas (purity: $75 \%$ ) to ambient pressure. During deposition, the gas inside the chamber was in a static state. The distance between the hot filament and substrate remained unchanged. The substrate temperature was controlled by adjusting electrical current on the hot filament, which was different from our previous experiments where the substrate temperature was controlled by simply changing the distance between the substrate and the hot filament.

\section{RESULTS AND DISCUSSIONS}

\subsection{Grows and characterizations}

Figure 1 shows typical SEM images of the nanostructured tungsten oxide films deposited on the AlN substrates at the substrate temperature of (a) $400^{\circ} \mathrm{C}$ and (b) $1000^{\circ} \mathrm{C}$, respectively. The experiments were conducted at ambient pressure and the duration for each sample was 30 minutes. Different morphologies were observed for different substrate temperatures, but otherwise identical growth conditions.

At $400^{\circ} \mathrm{C}$, nanowires with an average diameter of about $200 \mathrm{~nm}$ and length of about $1 \mu \mathrm{m}$ are uniformly distributed on the surface of sample (Figure 1(a)). Raising the substrate temperature to $1000^{\circ} \mathrm{C}$, the submicrometer size, well-shaped particles appear (Figure 1(b)).

From the naked eyes, the color of sample at $400^{\circ} \mathrm{C}$ appears green and dull. In contrast, following growth of substrate temperature to $1000^{\circ} \mathrm{C}$, slightly shiny surface was obtained. It should be mentioned that with further increase of substrate temperature, the color of obtained film would become white, and the particles on the surface of the substrate look like diamond particles, very shiny.

In general, the growth of thin film may follow three types of models: layer by layer growth of Franck and Van der Merwe (FM), initial layer growth followed by island growth of Stranski and Krastanov (SK), and the island growth of Volmer and Weber (VW). A determinant factor is the competition among the surface free energies of the overlayer $E_{o}$, the substrate $E_{s}$, and the overlayer/substrate interface free energy $E_{i}$. The common model is the case that the substrate free energies is low and $E_{s}<E_{o}+E_{i}$, where three dimensional island growth (VW) occurs [14]. The epitaxial growth of tungsten oxide was conducted, where the lattice constants differ from the AlN substrates, strains were introduced into the layer, which prevents epitaxial growth of thicker layers without defects [14]. Since we have large misfit between the film and the substrate, our case can possibly be considered as a VW model. Furthermore, the misfit in lattices between films and substrates can be enhanced with the increase of substrate temperature. Basically, the overlayer will grow with a stacking fault after a first coherent layer. When the film was much thicker than critical thickness, the initial smooth surface of the film will become the fractal-like structure, and eventually the thin film was transformed to nanoparticles shown in Figure 1.

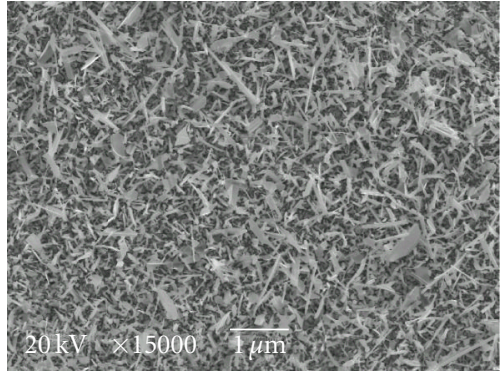

(a)

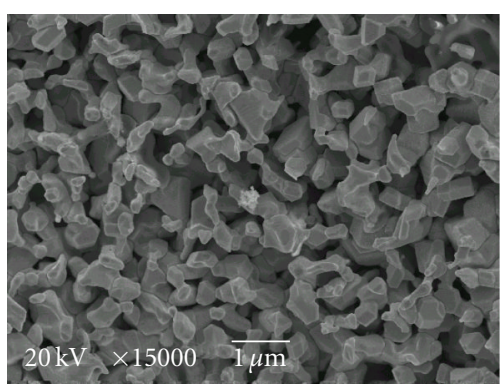

(b)

FIGURE 1: SEM images of the films prepared at substrate temperature of (a) $400^{\circ} \mathrm{C}$ and (b) $1000^{\circ} \mathrm{C}$.

Energy dispersive X-ray spectroscopy (EDX) measurements were also conducted to quantitatively analyze the chemical composition of the tungsten oxide samples (shown in Figures 1(a) and 1(b)). The oxygen and tungsten atom concentrations are approximately 62.47 at $\%$ and 30.21 at $\%$, respectively, for the first sample (Figure 1(a)). For the second one (Figure 1(b)), the oxygen concentration drops down to 55.78 at $\%$, whereas the relative tungsten content increases up to $41.62 \mathrm{at} \%$. The oxygen and tungsten concentration decreases from 2.07 to 1.34 from $400^{\circ} \mathrm{C}$ to $1000^{\circ} \mathrm{C}$.

Clearly, the concentration ratio $\mathrm{O} / \mathrm{W}$ is high at low temperature of deposition. With the increase of the substrate temperature, the concentration ratio $\mathrm{O} / \mathrm{W}$ decreases, probably resulting in a significant effect on the crystalline structures and the phase of the present two samples. In fact, the following XRD data have also shown distinct properties related to relative oxygen content inside the films.

Figure 2 shows XRD patterns of the two tungsten oxide samples in Figures $1(\mathrm{a})$ and $1(\mathrm{~b}) . \mathrm{WO}_{2}, \mathrm{WO}_{3}$, and $\mathrm{W}$ peaks in XRD spectra of the films have been identified based on the literatures $[15,16]$. The present two samples exhibit mixed states including $\mathrm{WO}_{2}, \mathrm{WO}_{3}$, and $\mathrm{W}$. The polycrystalline $\mathrm{WO}_{3}$ dominates the composition of the sample prepared at $400^{\circ} \mathrm{C}$. Evidence is that XRD peaks of $\mathrm{WO}_{3}$ with (002) and (200) orientations are much stronger than those of $\mathrm{WO}_{2}$ and $\mathrm{W}$ peaks. At $1000^{\circ} \mathrm{C}, \mathrm{WO}_{2}$ signals remain nearly unchanged but the $\mathrm{W}$ components become dominant with the vanishing of $\mathrm{WO}_{3}$ components. The XRD profiles of the films provide the direct evidence that the states of tungsten oxide films transfer from polycrystalline $\mathrm{WO}_{3}$ domination to polycrystalline $\mathrm{W}$ domination. 


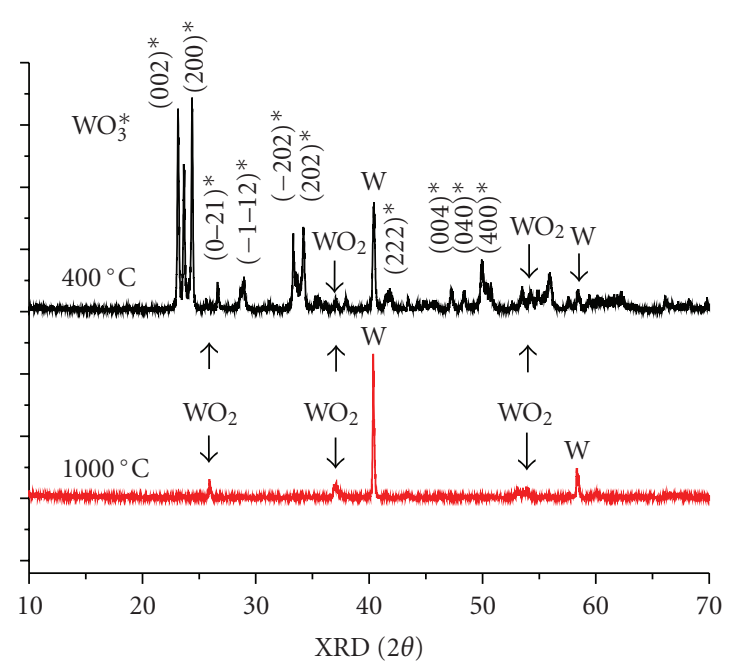

FIGURE 2: XRD of the tungsten oxide films corresponding to the samples shown in Figure 1.

Raman scattering spectra of the tungsten oxide films were also obtained at room temperature by using a triple monochromator (ISA J-Y Model T64000) with an excitation wavelength of $514 \mathrm{~nm}\left(\mathrm{Ar}^{+}\right.$ion laser). The samples were scanned from $50 \mathrm{~cm}^{-1}$ to $1200 \mathrm{~cm}^{-1}$. Several peaks marked with $\mathrm{J}$ and $\mathrm{k}$ in the Raman spectra were identified, respectively. In general, the bands situated at around 700 and $800 \mathrm{~cm}^{-1}$ can be assigned to $\mathrm{W}-\mathrm{O}$ stretching models, whereas the bands situated at around 130 and $270 \mathrm{~cm}^{-1}$ are associated to $\mathrm{W}-\mathrm{O}$ bending modes of monoclinic $\mathrm{WO}_{3}[16,17]$. It was also reported that $\mathrm{J}$ bands at 270 and $330 \mathrm{~cm}^{-1}$ can also be assigned to $\mathrm{W}-\mathrm{O}$ bending modes of monoclinic $\mathrm{WO}_{3}$ [18]. According to our case, $\mathrm{J}_{1}, \mathrm{~J}_{2}$, and $\mathrm{J}_{3}$ bands in Raman spectra of all our tungsten oxide samples always coexist. Therefore, the present three bands have been assigned to $\mathrm{J}$-bands associated to $\mathrm{W}-\mathrm{O}$ bending modes of monoclinic $\mathrm{WO}_{3}$.

Setting substrate temperature up to $1000^{\circ} \mathrm{C}$, both $\mathrm{K}$ bands and $\mathrm{J}$ bands were obviously broadened, and their signal-to-noise ratios greatly reduced, suggesting changes of states of the samples. This is in agreement with the data obtained from XRD above. A shoulder close to higher wave number of $\mathrm{WO}_{3} \mathrm{~K}$ bands is also clearly visible. According to literature, this shoulder (Raman band) should be related to the contribution from W component [16].

Slightly blue shifts of k bands from 711 to $719 \mathrm{~cm}^{-1}$ for $\mathrm{k}_{1}$ and from 806 to $808 \mathrm{~cm}^{-1}$ for $\mathrm{k}_{2}$ following an increase of the substrate temperature from 400 to $1000^{\circ} \mathrm{C}$ have been observed from Figure 3. Generally, the blue shifts of the Raman peaks probably result from the change in crystal symmetry or the high stress of the particles. The variations of content of $\mathrm{WO}_{2}$ and $\mathrm{W}$ inside unavoidably change crystal symmetry of $\mathrm{WO}_{3}$. However, referring to the previous work [19], the stress due to mismatch and the different thermal expansion between the substrate and overlayer is qualitatively associated with increasing the shift and width of the band. The blue shifts of the samples are also due to

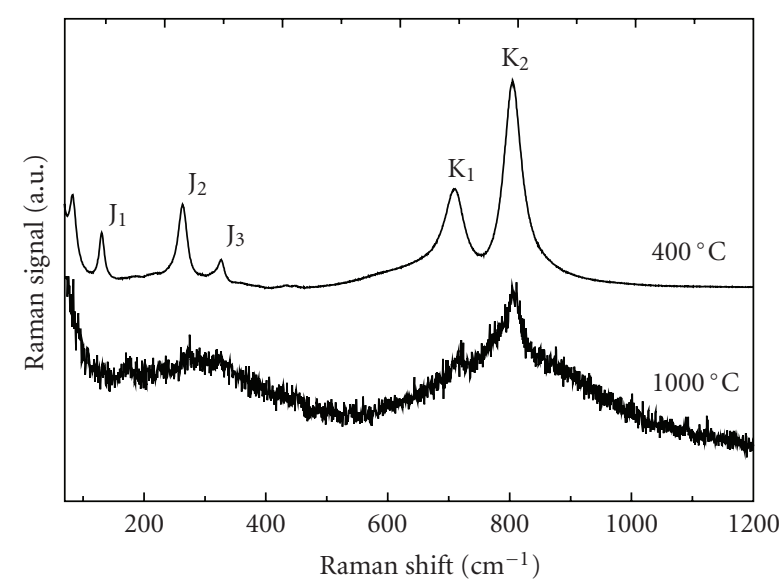

Figure 3: Raman spectra of the films at $400^{\circ} \mathrm{C}$ and $1000^{\circ} \mathrm{C}$.

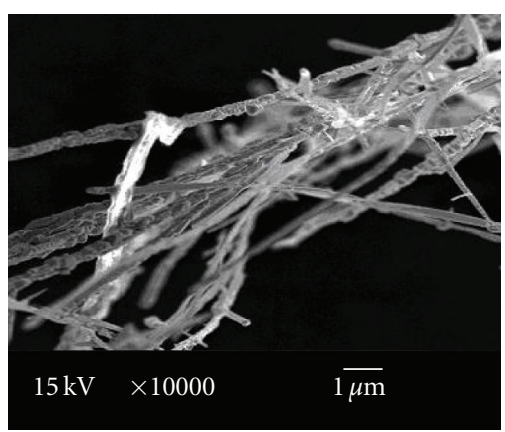

(a)

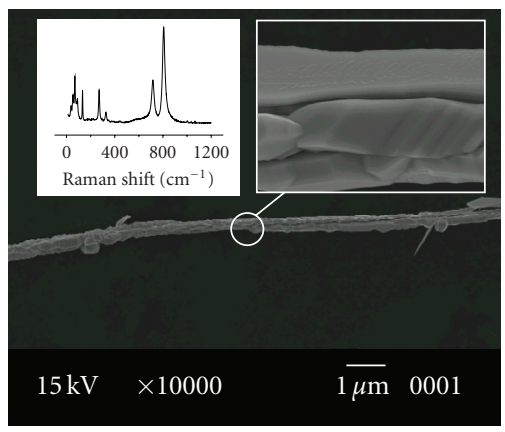

(b)

FIGURE 4: SEM images and Raman spectrum of the super long tungsten oxide wire-type nanostructures deposited on $\mathrm{Al}_{2} \mathrm{O}_{3}$ substrates at ambient pressure at $1000^{\circ} \mathrm{C}$.

the high stress of particles caused by the high temperature's deposition process.

Besides, it was found that different substrate materials also affected the tungsten oxide structures. Figure 4 shows the super long tungsten oxide nanowires deposited on $\mathrm{Al}_{2} \mathrm{O}_{3}$ substrates at ambient pressure with the substrate temperature $1000^{\circ} \mathrm{C}$. Bundles of wire-type tungsten oxide nanostructures with a length of up to $5 \mathrm{~mm}$ are distributed on the surface of $\mathrm{Al}_{2} \mathrm{O}_{3}$ substrate (Figure 4(a)). The average diameter of the nanowires is around $850 \mathrm{~nm}$. 


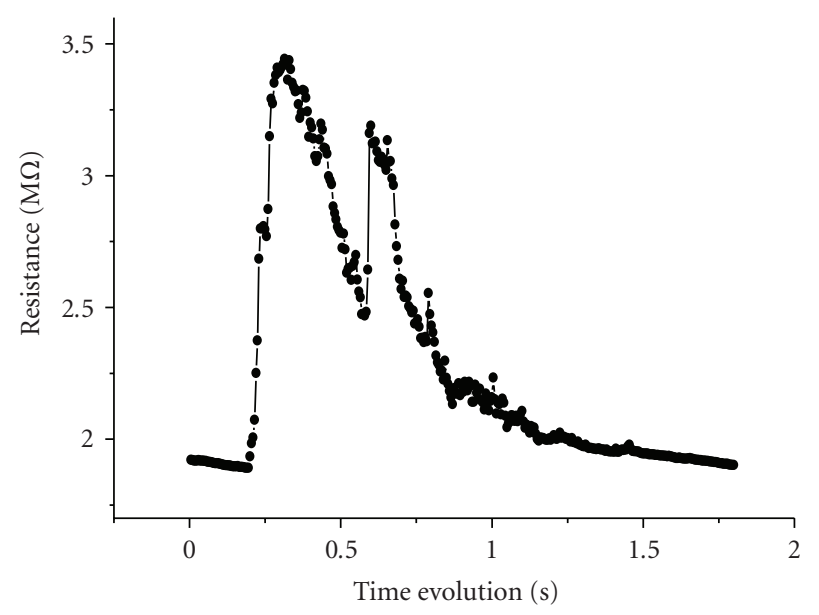

FIGURE 5: Evolution of sensitivity of nanowires after spraying methane gas.

From SEM images in Figure 4, it can be observed that each wire consists of good-shaped segments. Typical $\mathrm{WO}_{3}$ Raman spectrum has been obtained. The bands situated at 717.8 and $806.5 \mathrm{~cm}^{-1}$ are assigned to $\mathrm{W}-\mathrm{O}$ stretching models, whereas the bands situated at $133.9,272.1$, and $327.3 \mathrm{~cm}^{-1}$ are associated to $\mathrm{W}-\mathrm{O}$ bending modes of monoclinic $\mathrm{WO}_{3}$. The synthesis of super long tungsten oxide nanowires are probably related to the chemical reactions between the $\mathrm{Al}_{2} \mathrm{O}_{3}$ substrates and the tungsten oxide materials.

\subsection{The sensitive properties}

Furthermore, the sensitive properties of the super long nanowires were also investigated as an example. A prototypic sensor was constructed, which consisted of a voltagecurrent-resistor (V-I-R) electrical circuit. The tungsten oxide nanowires were serially connected to a precise resistor and a power supply. The variations of the voltage across the precise resistor were detected by using WaveSurfer 452 oscilloscope LeCroy Inc. (NY, USA), from which the variations of resistances or conductivities of tungsten oxide nanowires could be estimated. The measurements of the electrical conductivity were conducted in order to understand the variations of the sensitive properties of the sensor at different conditions.

For traditional sensors, a disadvantage is that the sensitivity of the sensor mainly relies on the operating temperature. The extra heater installed inevitably leads to the complicated geometry of the prototypic sensor [20, 21]. The following measurements were conducted at room temperature, and the sensitivity of the prototypic sensor to the gas was obtained.

A spraying nozzle was used to eject liquid methane as fine particles or gas to the surface of the nanowires. Flow distribution was determined by gas (air) and liquid superficial velocities. The electrical conductivities of the sensor during the whole process were recorded by National Instruments LabVIEW software.

The dependence of the sensitivity of tungsten oxide nanowires as a function of the time is shown in Figure 5.

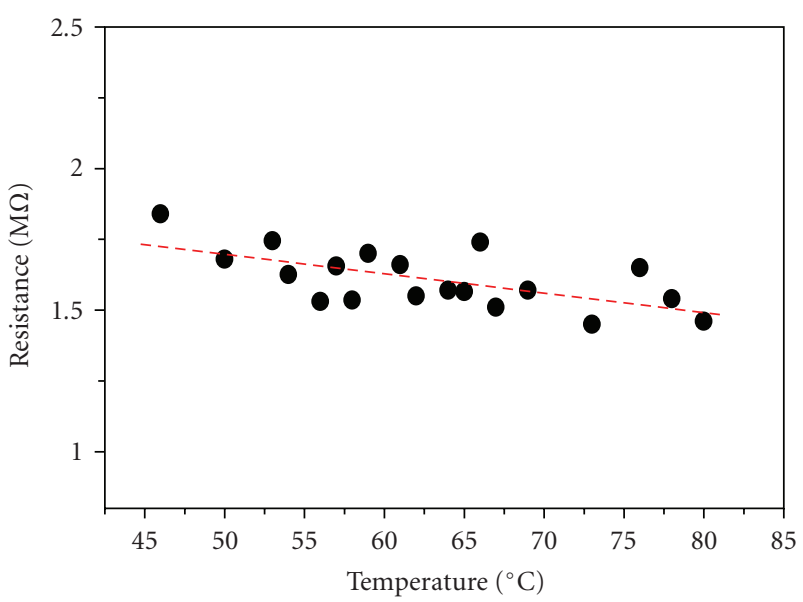

FIGURE 6: Variation of resistance of nanowires following the increase of temperature.

The response time (rise time) is about $90 \pm 0.5$ milliseconds, and recovery time of the sensor is around $550 \pm 0.5$ milliseconds, which depends on the solvent, gas, liquid superficial velocities from spraying nozzle, and spraying duration.

After heavily spray of liquid methane, an obvious multipeak type of sensitive variation would be observed, which was possibly caused by piston vibration inside the valve. Similar phenomenon was observed in our previous supersonic atomic beam experiments [22]. In general, the width and density of the second peak in the pulsed atomic beam profile are much smaller than the first one. Meanwhile, a weak spray would yield a single peak of molecular pulse, which consequently led to the weak response signal of the prototypical sensor.

Figure 6 shows the dependence of the resistance of tungsten oxide nanowires as a function of temperature. Clearly, the resistance of nanowires reduces from $1.75 \mathrm{M} \Omega$ to $1.49 \mathrm{M} \Omega$ with an increase of the temperature from $45^{\circ} \mathrm{C}$ to $80^{\circ} \mathrm{C}$ under atmosphere condition. Signal output of the prototypical sensor has almost linear relationship with the temperature.

\section{CONCLUSIONS}

Tungsten oxide nanoparticles and nanowires were synthesized at ambient pressure on AlN substratesusing the hot filament CVD techniques. The amount of $400^{\circ} \mathrm{C}$ of deposition yields $\mathrm{WO}_{3}$ film consisting of nanowires with an average diameter and length of about $200 \mathrm{~nm}$ and $1 \mu \mathrm{m}$, respectively. Increasing substrate temperature results in submicrometer size particles. The profiles of XRD of the films provide evidence of the mixture state changes from polycrystalline $\mathrm{WO}_{3}$ domination to polycrystalline W domination. Typical EDX measurements of the films indicated that the concentration ratio $\mathrm{O} / \mathrm{W}$ decreases from 2.07 to 1.34 from $400^{\circ} \mathrm{C}$ to $1000^{\circ} \mathrm{C}$. Up to $5 \mathrm{~mm}$ super long tungsten oxide nanowires with diameter of about $850 \mathrm{~nm}$ 
were obtained on $\mathrm{Al}_{2} \mathrm{O}_{3}$ substrate at $1000^{\circ} \mathrm{C}$, but otherwise identical growth condition.

Experiments have proved that tungsten oxide nanowires can be used for sensing applications. The resistance of nanowires reduces from $1.75 \mathrm{M} \Omega$ to $1.49 \mathrm{M} \Omega$ with an increase of the temperature from $45^{\circ} \mathrm{C}$ to $80^{\circ} \mathrm{C}$ under atmosphere condition. After spray of liquid methane, the rise time of the signal is about 90 milliseconds, and the recovery time for the sensor is around 550 milliseconds.

\section{ACKNOWLEDGMENTS}

This work was partially supported by NSF (DMR-0706147) and DoD (W911NF-07-1-0014). The authors would like to thank Mr. William for assistance of Raman measurements, and Mr. Josuel for SEM and EDX measurements.

\section{REFERENCES}

[1] I. E. Wachs, T. Kim, and E. I. Ross, "Catalysis science of the solid acidity of model supported tungsten oxide catalysts," Catalysis Today, vol. 116, no. 2, pp. 162-168, 2006.

[2] V. Khatko, G. Gorokh, A. Mozalev, et al., "Tungsten trioxide sensing layers on highly ordered nanoporous alumina template," Sensors and Actuators B, vol. 118, no. 1-2, pp. 255-262, 2006.

[3] F. Galléa, Z. Li, and Z. Zhang, "Growth control of tungsten oxide nanostructures on planar silicon substrates," Applied Physics Letters, vol. 89, no. 19, Article ID 193111, 3 pages, 2006.

[4] C.-Y. Kim, J.-W. Choi, T.-Y. Lim, and D.-K. Choi, "Synthesis of $\mathrm{WO}_{3}$ electrochromic sensor by sol-gel method and characterization of its electrochemical and optical properties," Key Engineering Materials, vol. 317-318, pp. 807-810, 2006.

[5] A. Romanyuk, R. Steiner, V. Melnik, and V. Thommen, "Ultrasound-assisted oxidation of tungsten in oxygen plasma: the early stages of the oxide film growth," Surface and Interface Analysis, vol. 38, no. 8, pp. 1242-1246, 2006.

[6] X. G. Wang, Y. S. Jang, N. H. Yang, L. Yuan, and S. J. Pang, "XPS and XRD study of the electrochromic mechanism of $\mathrm{WO}_{\mathrm{x}}$ films," Surface and Coatings Technology, vol. 99, no. 1-2, pp. 82-86, 1998.

[7] F. Di Fonzo, A. Bailini, V. Russo, et al., "Synthesis and characterization of tungsten and tungsten oxide nanostructured films," Catalysis Today, vol. 116, no. 1, pp. 69-73, 2006.

[8] M. Deepa, A. K. Srivastava, and S. A. Agnihotry, "Influence of annealing on electrochromic performance of template assisted, electrochemically grown, nanostructured assembly of tungsten oxide," Acta Materialia, vol. 54, no. 17, pp. 45834595, 2006.

[9] M. Deepa, P. Singh, S. N. Sharma, and S. A. Agnihotry, "Effect of humidity on structure and electrochromic properties of solgel-derived tungsten oxide films," Solar Energy Materials and Solar Cells, vol. 90, no. 16, pp. 2665-2682, 2006.

[10] T. Nanba and I. Yasui, "X-ray diffraction study of microstructure of amorphous tungsten trioxide films prepared by electron beam vacuum evaporation," Journal of Solid State Chemistry, vol. 83, no. 2, pp. 304-315, 1989.

[11] G. Gu, B. Zheng, W. Q. Han, S. Roth, and J. Liu, "Tungsten oxide nanowires on tungsten substrates," Nano Letters, vol. 2, no. 8, pp. 849-851, 2002.

[12] R. G. Palgrave and I. P. Parkin, "Chemical vapor deposition of titanium chalcogenides and pnictides and tungsten oxide thin films," New Journal of Chemistry, vol. 30, pp. 505-514, 2006.
[13] X. P. Wang, B. Q. Yang, H. X. Zhang, and P. X. Feng, “Tungsten oxide nanorods array and nanobundle prepared by using chemical vapor deposition technique," Nanoscale Research Letters, vol. 2, no. 8, pp. 405-409, 2007.

[14] P. X. Feng, X. P. Wang, H. X. Zhang, et al., "Study of the structural evolutions of crystalline tungsten oxide films prepared using hot-filament CVD," Journal of Physics D, vol. 40, no. 17, pp. 5239-5245, 2007.

[15] Yu. S. Krasnov, S. V. Volkov, and G. Ya. Kolbasov, "Optical and kinetic properties of cathodically deposited amorphous tungsten oxide films," Journal of Non-Crystalline Solids, vol. 352, no. 38-39, pp. 3995-4002, 2006.

[16] Z. Lu, S. M. Kanan, and C. P. Tripp, "Synthesis of high surface area monoclinic $\mathrm{WO}_{3}$ particles using organic ligands and emulsion based methods," Journal of Materials Chemistry, vol. 12, no. 4, pp. 983-989, 2002.

[17] K. Nonaka, A. Takase, and K. Miyakawa, "Raman spectra of sol-gel-derived tungsten oxides," Journal of Materials Science Letters, vol. 12, no. 5, pp. 274-277, 1993.

[18] Z. Xiao, L. Zhang, X. Tian, and X. Fang, "Fabrication and structural characterization of porous tungsten oxide nanowires," Nanotechnology, vol. 16, no. 11, pp. 2647-2650, 2005.

[19] Y. Shigesato, A. Murayama, T. Kamimori, and K. Matsuhiro, "Characterization of evaporated amorphous $\mathrm{WO}_{3}$ films by Raman and FTIR spectroscopies," Applied Surface Science, vol. 33-34, pp. 804-811, 1988.

[20] Y. S. Kim, S.-C. Ha, K. Kim, et al., "Room-temperature semiconductor gas sensor based on nonstoichiometric tungsten oxide nanorod film," Applied Physics Letters, vol. 86, no. 21, Article ID 213105, 3 pages, 2005.

[21] V. Khatko, E. Llobet, X. Vilanova, et al., "Gas sensing properties of nanoparticle indium-doped $\mathrm{WO}_{3}$ thick films," Sensors and Actuators B, vol. 111-112, pp. 45-51, 2005.

[22] P. X. Feng and B. Weiner, "A collimated pulsed supersonic metastable helium atomic beam," Physica Scripta, vol. 75, no. 4, pp. 565-571, 2007. 

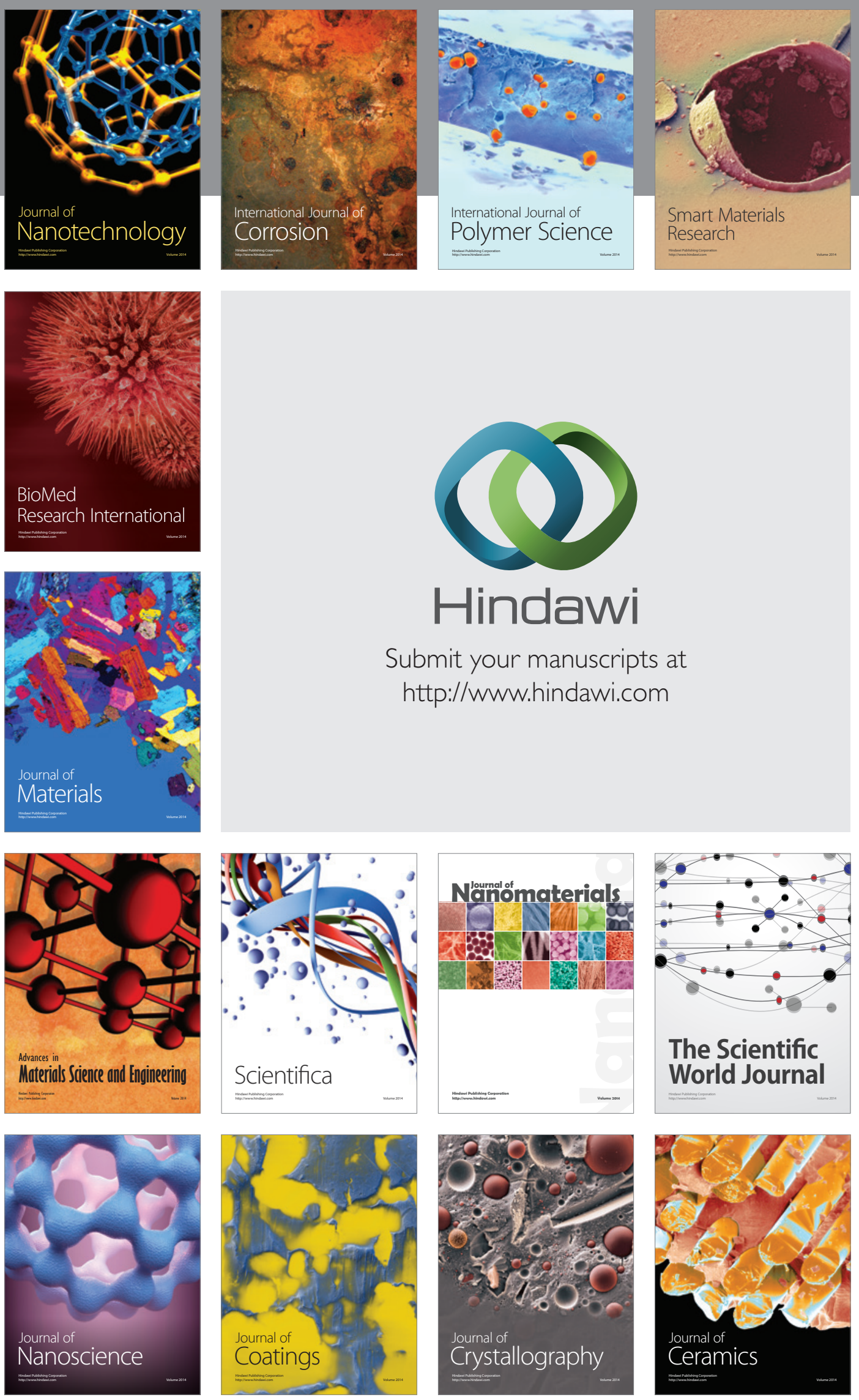

The Scientific World Journal

Submit your manuscripts at

http://www.hindawi.com

\section{World Journal}

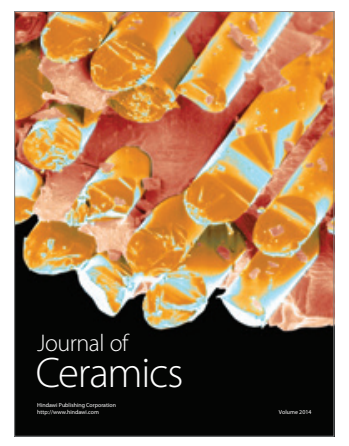

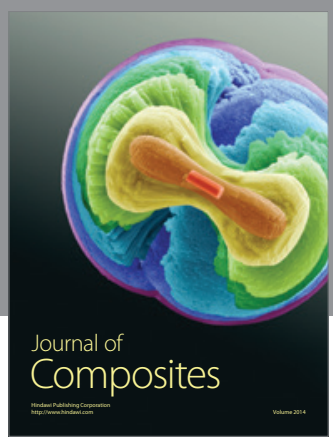
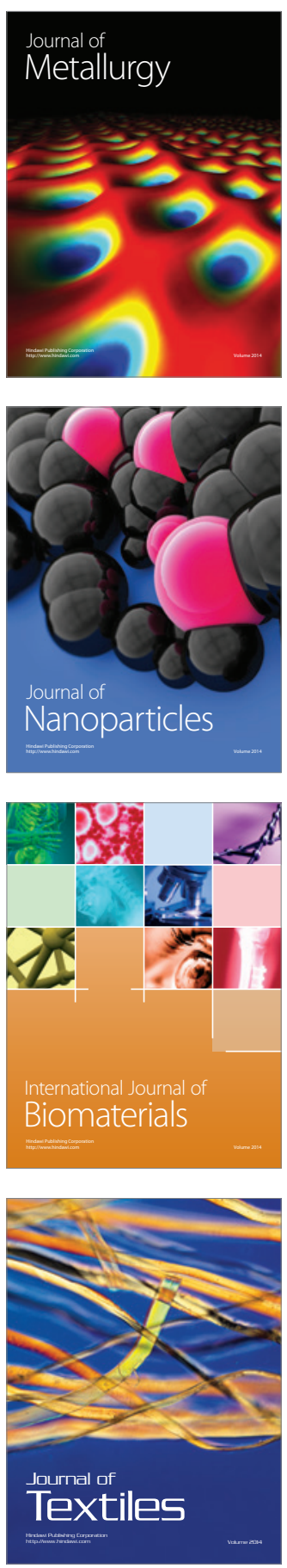